\title{
O efeito do sexo: políticas de raça, gênero e miscigenação*
}

\author{
Osmundo de Araújo Pinho**
}

\begin{abstract}
Resumo
Este artigo propõe uma discussão das implicações políticas $e$ teóricas da miscigenação como uma formação discursiva, que produz como seu centro a figura idealizada e essencializada do mestiço - mulata ou mulato. Em segundo lugar, toma o caso concreto da construção de duas figuras de gênero racializadas no ambiente da chamada reafricanização da cultura e da política em Salvador: o brau e a beleza negra. O primeiro, uma performance masculina hiper-sexualizada e agressiva, marcada por releituras juvenis vernáculas da "cultura" funk-soul; a segunda, um ideal de mulher $e$ de beleza feminina, oscilante entre políticas de identidade e formas de subjetivação definidas pela relação com o mercado. Em ambos os casos, observa-se a encenação de uma crítica prática ao "regime de verdade" da miscigenação.
\end{abstract}

Palavras-chave: Miscigenação, Reafricanização, Beleza Negra,

Brau.

\footnotetext{
* Recebido para publicação em agosto de 2004, aceito em setembro de 2004. Este artigo foi preparado a partir de trechos dos capítulos II e III de minha tese de doutorado - O mundo negro: sócio-antropologia da reafricanização em Salvador - defendida na UNICAMP em março de 2003.

*** Diretor do Centro de Estudos Afro-Brasileiros da Universidade Candido Mendes, Rio de Janeiro-RJ, Brasil.opinho@candidomendes.edu.br
} 
O efeito do sexo

The Effect of Sex:

Race, Gender and Miscegenation Politics

\begin{abstract}
This article discusses political and theoretical implications of miscegenation as a discursive formation, which engenders in its center the idealized character of the mestizo - mulatto. Secondly, it takes the concrete case of two racialized gender figures in the context of the so called re-Africanization of culture and politics in Salvador, Brazil: brau and black beauty. The first, a hypersexualized male performance, characterized by youth vernacular re-readings of the funk-soul "culture", and the second, an ideal of woman and female beauty oscillating between identity politics and subjectification forms defined by the relationship with the consumer market. In both cases there is a game constructed from a practical critique of the "truth regime" of miscegenation.
\end{abstract}

Key Words: Miscegenation, Reafricanization, Black Beauty, Brau. 
Osmundo de Araújo Pinho

\section{Introdução: a miscigenação como formação discursiva}

Neste artigo, abordo certa economia política da raça e do gênero, em suas conexões diferenciais, a partir de duas perspectivas. Primeiro, discuto brevemente a história da formação discursiva da miscigenação, que opera por estruturar discursivamente $-e$ isso quer dizer também materialmente - raça, sexualidade e identidade nacional de modo a instituir um campo de leituras, interpretações, sujeitos, todo um "regime de verdade", que pressupõe uma figura idealizada e essencializada de "mestiço" - a mulata ou mulato - como base para a transformação modernizante e modernista da sociedade brasileira naquilo que ela é, como vontade e como representação. Essa formação discursiva é o cimento ideológico que nos permite, por outro lado, "ler" de modos muito concretos e posicionados determinada cultura sexual e de gênero, como uma variante da especificidade nacional-racial brasileira. Espero poder sugerir que gênero e sexo enraízam-se assim como operadores prático-discursivos da reprodução social como reprodução biológica.

Num segundo momento, tomo o caso concreto da emergência de duas figuras de raça e gênero, surgidas no âmbito do processo conhecido como reafricanização da cultura e da política em Salvador. Este processo é entendido como uma inflexão modernizante e auto-reflexiva das identidades negras em Salvador, desencadeada a partir dos anos setenta, na confluência da redemocratização da sociedade brasileira com os fluxos internacionais da diáspora africana global. Em primeiro lugar, apresento o brau, personagem masculina e racializada, que performa de modo contraditório e ambivalente a hipersexualização em geral atribuída a homens negros, em uma conexão juvenil com a cultura funk-soul norte-americana. Em segundo lugar, exploro a formação de um novo ideal de feminilidade negra, construída contra estereótipos raciais-sexuais da mulata, da doméstica e da baiana de acarajé. Este novo ideal foi forjado, principalmente, no âmbito dos concursos de beleza do 
O efeito do sexo

bloco afro Ilê Aiyê, símbolo da "integridade" racial na Bahia reafricanizada, mas também se articula com a expansão do mercado e com a mercadificação da identidade negra. Tanto o brau, como a beleza negra, por outro lado, se colocam do lado oposto dos discursos miscigenantes e significam um desafio às formas codificadas de leitura para raça, gênero e corpo. Essas novas leituras expõem a crise das representações sobre a nação, justamente configuradas pelo modo peculiar de conjurar a identidade de um povo por intermédio da sexualidade como motor da história.

\section{A miscigenação canibal: o homem branco, o sexo e a assimilação}

O pensamento sobre as raças, a questão da miscigenação $e$ o Problema Negro se transferem da área de influência dos estudos racialistas para os estudos etnológicos dos anos 30-40, permanecendo como substrato para a compreensão das relações raciais por meio da essencialização da miscigenação, fiel da balança da unidade cultural nacional. Nesse caso, a "cultura" é o sustentáculo de um arranjo político e econômico, que se reproduz desigualmente, ao mesmo tempo em que ideologiza as diferenças sociais como diferenças naturais-culturais. A sexualidade $e$ as relações de gênero aparecem como mediadores nucleares nesse caso.

Em Nina Rodrigues, a questão racial aparece como um conflito entre a civilização, representada pelos brancos, e o crime, a loucura $e$ o fetichismo, representado pelos negros $e$ seus descendentes. ${ }^{1}$ A formação da consciência intelectual nacional parece assim desenvolvida contra a autoconsciência nacional em formação.

A perspectiva científica, forjada de um ponto de vista europeu, encontrava sua contradição em um país como o Brasil,

1 Rodrigues, Nina. O Animismo Fetichista dos Negros Baianos. Prefácio e Notas de Artur Ramos. Rio de Janeiro, Civilização Brasileira, 1935 [1909]; Os Africanos no Brasil. 5 edição. São Paulo, Brasiliana/Cia Editora Nacional, 1977. 
que procurava consolidar-se como uma nação européia segundo os interesses de sua elite, ansiosa por conectar-se aos fluxos dinâmicos do capitalismo e que, ao mesmo tempo, teria que se reconhecer, inclusive pelo olhar estrangeiro, como muito pouco ocidental ou branca para seus próprios padrões. A herança da escravidão estava ali, materializada na pletora de cores e costumes bizarros, mulatos pelas ruas sambando e negras histéricas caindo no transe. A tarefa da ciência se colocava como uma tarefa higienizadora da nação. Como Lilia Schwarcz ${ }^{2}$ coloca, o problema não parecia tanto a doença, mas o doente, e doente estaria toda nossa população manchada pela miscigenação. Como transformar essa massa informe e multicolorida em um povo, uma raça, que preservasse o caráter e aparência de uma civilização branca?

Ao responder a essas questões o projeto intelectual da Escola Nina Rodrigues manifestava-se como francamente autoritário e destinava-se, na sua vertente antropológica ou médica, ao controle social. Este controle assume a dupla face de um controle racial e de um controle político de classe. O "elemento negro" ameaçava invadir o mundo branco, destruí-lo. Em seu contágio transforma o branco, ou o assim suposto, em outra coisa que ele temia e odiava. Uma coisa representada pela escura face mestiça da população. Assim, em Nina e em outros epígonos da época, a mestiçagem e o negro, o povo e as massas, aparecem como um óbice à civilização $e$ se definem como um perigo interno biologicamente materializado nas raças que penetram no corpo social, marcando, como um fundamento apriorístico, o destino moral e social da nação. ${ }^{3}$ Os homens aparecem aqui, mais uma vez, prisioneiros das categorias sociais que eles mesmos criaram para instituir o mundo e uma ordem

2 Schwarcz, Lilia Moritz. O Espetáculo das Raças. Cientistas, Instituições e a Questão Racial no Brasil 1870-1930. São Paulo, Cia das Letras, 1995.

3 ID. IB.; CoRRÊA, Mariza. As Ilusóes da Liberdade: A Escola Nina Rodrigues e a Antropologia no Brasil. 2 edição revista. Bragança Paulista, FAPESP/EDUSF, 2001. 
O efeito do sexo

social determinada, quanto mais injusto e brutal esse mundo parecia, mais terríveis as categorias se tornavam.

As ciências sociais que se formavam nos anos trinta herdaram este pesado pacote discursivo e diante dele propuseram uma saída comum, representada tanto em Freyre como em Ramos. A miscigenação é inoculante, trouxe um elemento genético, atávico, que se representa como uma diferença essencializada. Esta inoculação, entretanto, não é degenerativa, mas generativa e deve se manifestar como assimilação ou aculturação. O que fora interpretado de modo destrutivo, como semente para o conflito, passa a ser visto em nova chave como algo que se incorpora alimentando a nação, como seu substrato profundo, uma seiva interna que fluía secularmente da África e das florestas, formando o povo brasileiro, síntese de contradições.

Para que essa saída de emergência (para o problema da mestiçagem) se apresentasse o conceito de cultura teria que ser introduzido. Ora, Freyre desponta no horizonte das idéias como o introdutor da substituição de raça por cultura. Assim também, Arthur Ramos, disputando, ao mesmo tempo que Freyre, o legado de Nina, coloca-se como o grande revisor da obra do Mestre Maranhense, justamente substituindo a noção de raça pela de cultura. E nesse ponto, quero chamar a atenção para a conexão feita como uma transição entre dois termos que se substituem para recompor o mesmo jogo discursivo. Como está explicitamente colocado em Ramos:

Muito depois haveria de se provar que o pretenso mal da mestiçagem é um mal de condições deficientes de meio social e cultural. Se substituirmos na obra de Nina Rodrigues os termos biológicos de Raça e Mestiçamento pelas noções de CULTURA e Aculturação, as concepções adquirirão completa e perfeita atualidade. ${ }^{4}$

${ }^{4}$ RAmOS, Arthur. Introdução à Antropologia Brasileira. Os Contatos Raciais e Culturais. $3^{\circ}$ volume. $3^{\text {a }}$ edição, Rio de Janeiro, Livraria Editora da Casa do Estudante Brasileiro, 1962, p.57. 
Nesta estratégia discursiva, o termo, se raça ou cultura, não importa tanto assim, o que importa é criar condições para que se produza um povo adequado aos imperativos da civilização ou do progresso. Como coloca Corrêa:

A trajetória da desgraça teórica em qual caiu a definição de raça, e sua substituição pela de cultura, aponta assim menos para uma ruptura definitiva com que se poderia chamar paradigma determinista do que por uma continuidade entre ambas $e$, em todo caso, a sua pertinência ao mesmo universo de sentido que a história da constituição da escola [Nina Rodrigues] esclarece. ${ }^{5}$

O que a história da escola esclarece é a imbricação entre interesses de controle e disciplinamento social, metamorfoseados como preocupações eugênicas, sanitaristas, médicas, psiquiátricas. O que em Nina aparecia como um desafio, "esfinge do presente", a demandar um esforço de superação pelo bem do interesse nacional, reaparece em Ramos e em Freyre como aculturação e miscigenação, em uma palavra, assimilação. Agora, a questão é como transformar a massa desordenada de cafuzos e mulatos em parte integrante do corpo nacional, deglutí-los, canibalizá-los, como na inspiração modernista, tão loquaz na formação do imaginário freyreano. ${ }^{6}$

Raça e cultura participam de um mesmo continuum estratégico, inserido no movimento mais amplo de acomodação entre uma elite branca, ou orientada por valores simbolizados como brancos e ocidentais, e a grande maioria da população, num ambiente de modernização. Este encontro tenso, tantas vezes

${ }^{5}$ CORRÊA, M. As Ilusóes da Liberdade... Op. cit., p.258.

${ }^{6}$ NUNES, Zita Cristina. Race, Miscigenation, and the Construction of a National Identity: The Modernist Period in Brazil. Tese de Doutorado, University of California at Berkeley, 1994. 
O efeito do sexo

tematizado nas artes e na cultura popular nacionais, atravessa a história deixando para trás um rastro de carne e sangue.

Repetido através de suas mutações, vemos o mesmo movimento de incorporação de uma população inoculante transformada de tabu em totem por uma elite antropófaga. Esta passagem parece tornada possível justamente pela mutação da natureza (raça) em cultura. Uma passagem canibal, metaforizada em inúmeros objetos da cultura e na própria associação entre $\mathrm{o}$ ato sexual $e$ a deglutição, metáfora amplamente reforçada e enraizada por todo o imaginário sexual no Brasil e convenientemente amplificada pelo modernismo de 1922: "Só a antropofagia nos une. Socialmente. Economicamente. Filosoficamente." 7

A mestiçagem, câncer que corroia a pretensão branca, torna-se elemento operador da integração nacional e ao mesmo tempo de sua modernização, caracterizada como subordinante.

Para Ramos, junto a Freyre o grande conversor deste período, a problemática das diferenças raciais deveria ser reduzida à problemática das diferenças culturais e dos contatos entre as culturas. A discussão sobre a mestiçagem estaria contaminada por mitos e estereótipos dos quais cabia a ciência desincumbir-se. Sendo assim, a questão da mestiçagem deveria ser substituída pela problemática, mais adequada aos avanços da ciência, da aculturação. $^{8}$

Apesar das disputas pela herança de Nina, e das diferenças supostas, Freyre e Ramos tinham mais em comum do que gostariam. ${ }^{9}$ Não é necessário repetir aqui todo o arrazoado freyreano sobre a miscigenação. Sabemos que em Casa grande \& senzala este autor analisa a formação da sociedade e da cultura brasileira através do complexo patriarcal escravista, definido no

7 AndRADE, Oswald. Manifesto da Poesia Pau-Brasil. Manifesto Antropófago. O Rei da Vela. Rio de Janeiro, Paz e Terra, Coleção Leitura, 1996 [1928], p.19.

8 RAmos, A. Introdução à Antropologia Brasileira... Op. cit.

9 CorrêA, M. As Ilusões da Liberdade... Op. cit.. 
período colonial, assim pôde descrever "proustianamente" as interações entre os grupos raciais/culturais em contato no ambiente escravista como conduzindo, através da acomodação, a uma síntese de antagonismos alojada nas estruturas sociais $e$ colorida pelas relações pessoais favorecidas pela intimidade hierarquizada entre escravos e senhores. ${ }^{10}$

Caracterizado como uma sociedade híbrida, o Brasil colonial parece ter sido favorecido por um ambiente de "quase reciprocidade cultural". ${ }^{11}$ Freyre, que repete de Nina a crença na superioridade "sudanesa", que teria proporcionado ao Brasil "o melhor da cultura negra", atribui ao negro a participação fundamental na formação da alma nacional. O trecho é muito citado, mas vale a pena revê-lo: "Todo brasileiro, mesmo o alvo, de cabelo louro, traz na alma, quando não na alma e no corpo (...) a sombra ou pelo menos a pinta do indígena ou do negro". ${ }^{12}$

Em Sobrados e mocambos, a mestiçagem ganha outros papéis. Se no livro anterior representou a formação do caráter nacional e a incorporação do "melhor da cultura negra" ao caráter nacional, neste, a miscigenação aparece como um aspecto da modernização do país. O mulato bacharel representa e encarna o elemento de transição entre uma sociedade agrária e escravocrata em decadência e uma sociedade modernizada e urbana, marcada pelo trabalho livre. A transição modernizante do século XIX no Brasil parece caracterizada pela formação de uma mão-de-obra de cor livre e urbana. Em grande número, notadamente no Nordeste, esta mão-de-obra é parda ou de cor, pois mulatos e

${ }^{10}$ FreYre, Gilberto. Casa Grande \& Senzala. Introdução à História da Sociedade Patriarcal no Brasil. 30 edição. Rio de Janeiro, Record, 1995 [1933]. BASTOS, Elide Rugai. Gilberto Freyre. Casa-Grande \& Senzala. In: MotA, Lourenço Dantas. Introdução ao Brasil. Um Banquete no Trópico. São Paulo, $2^{a}$ ed., SENAC, 1999, pp.217-233. ARAúJO, Ricardo Benzaquen. Guerra e Paz. Casa Grande \& Senzala e a Obra de Gilberto Freyre nos Anos 30. São Paulo, Editora 34, 1994.

${ }^{11}$ Freyre, G. Casa Grande \& Senzala... Op. cit., p.91.

12 ID., IB., p.283. 
O efeito do sexo

mestiços teriam ocupado um nicho específico intermediário no mercado de trabalho ou na estrutura das classes. Ao mesmo tempo são a encarnação de valores médios, transigidos, híbridos ou mestiçados, herdando tanto da cultura branca como da negra, realizando outra síntese modernizante, no sentido de construir a passagem sem traumas de uma sociedade estamental para outra aberta. Esta abertura é justamente incorporada pelo mulato. Como coloca Thales de Azevedo, anos depois, a mestiçagem é uma expressão "do dinamismo social intrínseco de uma sociedade multi-racial". ${ }^{13}$

A mestiçagem representa o movimento contra o imobilismo das castas ou do regime patriarcal e uma vitória da urbanização e da modernização da sociedade. O mestiço, conceitual e concreto, é o portador da mudança e da passagem, de uma passagem que nunca se completa, mas se repõe constantemente. É, além do mais, o símbolo da mobilidade social permitida por uma sociedade que se representa fluida, aberta e dinamizada pela mestiçagem.

E o mulato é, em traços mais evidentes, o que a raça é, em traços mais pálidos: a negação do biologicamente estático no homem ou no grupo. A afirmação mas clara da mobilidade biológica das raças. ${ }^{14}$

Parece claro que para Freyre a miscigenação significa a incorporação do elemento negro (escravo) na cultura nacional, sendo, nesse sentido, assimilação. Não podemos esquecer que esta assimilação representa o êxito, enaltecido por Freyre, do projeto colonial português no Brasil, o que faz parecer totalmente

${ }^{13}$ Azevedo, Thales. As Elites de Cor numa Cidade Brasileira. Um Estudo de Ascensão Social \& Classes Sociais e Grupos de Prestígio. Salvador, Empresa Gráfica da Bahia/EDUFBA, 2a ed., 1996 [1955], p.1.

${ }^{14}$ FreYRE, Gilberto. Sobrados e Mucambos. Decadência do Patriarcado Rural e Desenvolvimento do Urbano. $12^{a}$ ed., Rio de Janeiro, Record, 2000 [1936], p.686. 
coerente os desenvolvimentos tropicológicos posteriores de apologia à cultura portuguesa, ao colonialismo português nos século XX e à ditadura Salazar. ${ }^{15}$

Ora, o português é o elemento branco na formação nacional. Enaltecendo o português, Freyre reconduz o Homem Branco ao centro dos dinamismos coloniais e deixa claro que o projeto miscigenado significa a vitória da ocupação portuguesa nos trópicos. O homem brasileiro é o português "melhorado" pelo cruzamento racial e biológico que o fez triunfar nos trópicos. A diferença cultural é, desse modo, deglutida em nome de um projeto de estado e nação. Como Freyre coloca claramente, a questão era ocupar e civilizar o país:

Tenhamos a honestidade de reconhecer que só a colonização latifundiária e escravocrata teria sido capaz de resistir aos obstáculos enormes que se levantaram à civilização do Brasil pelo europeu. Só a casa-grande e a senzala. ${ }^{16}$

Somente o português e seu "colaborador" escravo poderiam cumprir a tarefa de tornar a este país uma nação. Nesta epopéia ufanista quase podemos ouvir ecos imperialistas da voz marítima de Camões:

As armas e os barões assinalados

Que, da ocidental praia lusitana,

Por mares nunca dantes navegados

Passaram ainda além da Taprobana,

Em perigos e guerras esforçados,

Mais do que prometia a força humana,

${ }^{15}$ Freyre, Gilberto. Nôvo Mundo nos Trópicos. São Paulo, Brasiliana/Cia Editora Nacional/EDUSP, 1971. THOMAZ, Omar Ribeiro. Do Saber Colonial ao Luso-Tropicalismo: "Raça" e "Nação" nas Primeiras Décadas do Salazarismo. In: MaIO, Marcos C. \& SAnTos, Ricardo V. (orgs.) Raça, Ciência e Sociedade. Rio de Janeiro, Editora Fiocruz/Centro Cultural Banco do Brasil, 1996, pp.85-106.

${ }^{16}$ Freyre, G. Casa Grande \& Senzala... Op. cit., p.244. 
O efeito do sexo

E entre gente remota edificaram

Novo reino, que tanto sublimaram. ${ }^{17}$

Ora, esta "gente remota" somos nós. Mas como podemos ser, ao mesmo tempo, os descendentes desta e dos "barões assinalados"? Parece assim que a consciência nacional estaria fundamentalmente fraturada pela duplicidade de uma posição que se reivindica descendente tanto dos colonizadores $e$ conquistadores, a elite canibal a qual me referi, como dos nativos, a gente remota, os povos de cor subjugados no turbilhão colonial de esperma e sangue.

Esta contradição parece resolvida em Freyre pela mestiçagem que, a um só tempo refunda uma perspectiva histórico-genética para a formação da nacionalidade; elege uma estratégia como uma saída de emergência para a mobilidade e a mudança sociais encarnadas na figura do mulato; e desqualifica qualquer reivindicação de autenticidade cultural afrodescendente, o que poderia fomentar a formação de um sujeito político autônomo, porventura mais modernizante do que o mulato parece ter sido (haja vista a modernização a que chegamos).

Esta identificação afrodescendente seria - e ainda é -, sobretudo, negada: negros não formam um corpo determinado apartado do país, nem histórica, nem cultural, nem socialmente e, apesar de hoje em dia ser difícil negar a apartação econômica, a comunhão espiritual parece ser tamanha que impede a dissolução do doce vínculo da miscigenação. Nesse sentido, a síntese freyreana, como um instrumento de conversão ideológica, favoreceu a imobilidade - bem descrita nas estatísticas raciais exatamente ao tentar demonstrar a modernização pela mestiçagem. ${ }^{18}$

${ }^{17}$ CAmÕes, Luís de. Os Lusíadas. São Paulo, Ática, 1997, p.31.

${ }^{18}$ DegleR, Carl. Nem Preto Nem Branco. Escravidão e relaçóes raciais no Brasil e no E.U.A. Rio de Janeiro, Editorial Labor do Brasil, 1976; MuNANGA, Kabengele. Rediscutindo a Mestiçagem no Brasil. Identidade Nacional versus Identidade Negra. Petrópolis, Vozes, 1999. Interrogando sobre as diferenças 
Todo este debate usa de forma espúria as bases "reais" da miscigenação biológica, que só pode parecer tão saliente na medida em que imaginemos que uma diferença racial essencial separa grupos humanos como brancos, negros, etc. É óbvio e auto-evidente que sem raças não pode haver miscigenação. Esta miscigenação racial é pensada facilmente em termos culturais em virtude da comunicação que existe entre os dois termos na história da formação dos Estudos Afro-Brasileiros. Seja com relação aos discursos oficiais sobre a miscigenação, seja com relação às práticas concretas, dispersas e multi-variadas, os temas da miscigenação, para o caso brasileiro, parecem comprometidos com a história da dominação racial de modo irrevogável, com a história da consolidação de um pensamento propriamente racial, que tem a invencível propriedade de fazer-se presente sem estar pronunciado e de produzir efeitos sem ser identificado. No conjunto dos procedimentos ideológicos de fabricação do consenso, o mestiço aparece ontologizado, está posto. Em nome da clareza e da justiça seria desejável vê-lo deposto?

Acredito, por outro lado, não ser possível exagerar o aspecto sexual, ou talvez "desejante", dos discursos sobre a mestiçagem no Brasil. Desde os jesuítas, atolados nas carnes indígenas, até o imaginário contemporâneo da indústria cultural, associa-se à miscigenação, projeto nacional, o sexo, o prazer e o desejo, projetos subjetivantes. Uma forma, talvez engenhosa, de pensar a relação entre indivíduo e sociedade, mediada pelo sexo, pelo corpo $e$ pelos genes. Produzir a nação e a cultura nacional em diversas versões da mística miscigenante é fazer sexo. Mas o

entre o padrão racial brasileiro e o norte-americano, Carl Degler segue a mesma trilha e acredita que o mulato seja o locus desta diferença. Melhor dizendo, a saída de emergência do mulato permitiu, em virtude de diferenças demográficas e históricas, que se formasse no Brasil um estrato intermediário, médio, de mulatos ou homens de cor livres, criando-se um lugar especial e separado para os mestiços. De qualquer modo, para Degler a miscigenação parece se constituir como um fator possibilitador da mobilidade social e da transformação das estruturas sociais exatamente como em Freyre. 
O efeito do sexo

sujeito desta sexualidade, já vimos, é o homem branco heterossexual, que se representa como o civilizador erótico.

O português, segundo Freyre, seria um intoxicado sexual. No ambiente da escravidão e da subordinação física e brutal de outros seres humanos, encontrou cenário perfeito para expressão dessa sua característica peculiar. A sexualidade exercida e representada em contextos de desigualdade e assimetria parece ser assim o operador da miscigenação predatória e o elo de ligação entre os diferentes extratos sociais que se reproduzem como diferentes através do exercício direto do desejo e do controle branco sobre o corpo do Outro e sua simbolização. Não seria, nesse sentido, extraordinária a hipótese de que escravidão, ela mesma, teria um componente voluptuoso, além daquele propriamente econômico ou cultural, e essa parece ser a mensagem mais ou menos implícita em Freyre. Ter um escravo ou escrava, como um objeto perfeito, pleno e legalmente caracterizado, um objeto, é bem verdade, muito especial, na medida em que é um ser humano, pareceria o paroxismo da objetivação carnal.

Não parece casual a conjunção de instâncias diversas de articulação e produção do poder com privilégios sexuais $e$ intercursos raciais biológicos. Teríamos, parafraseando Sahlins ${ }^{19}$, uma economia política da sexualidade? $\mathrm{Na}$ sociedade havaiana pré-colonial, nos ensina esse autor, a sexualidade estruturava as desigualdades sociais de alto a baixo, num paralelo algo perturbador com a realidade brasileira, marcada pela intimidade entre os desiguais:

Tanto para o povo quanto para os chefes, o efeito do sexo era a sociedade: um conjunto de relações mutantes que gradualmente se arrumavam e adquiriam permanência devido às considerações práticas a ele associadas. ${ }^{20}$

${ }^{19}$ SAHLINS, Marshall. Ilhas de História. Rio de Janeiro, Jorge Zahar Editor, 1990.

${ }^{20}$ ID., IB., p.43, ênfase adicional. 
O encontro colonial, no caso havaiano, foi um encontro sexual, como está admiravelmente descrito em Sahlins, porque o sexo era uma estratégia de articulação social dos nativos e, em um sentido diferente, instrumento de realização de si para os colonizadores. No caso brasileiro, marcado pela posse dos corpos racializados, a sexualidade, a mestiçagem $e$ a racialização parecem caminhar juntas, formando a identidade nacional como uma "estrutura da conjuntura", marcada pelo abuso e pela reificação subordinante da alteridade, ao mesmo tempo como objeto de desejo e de controle social. Não existe, poderíamos dizer, desejo fora da história e não existe história sem conflito e sublevação. A história das relações raciais como relações miscigenadas parece solidária à história da construção dos paradigmas da sexualidade nacional vista, como bem apontou Parker ${ }^{21}$, como marca da identidade brasileira, representada em inúmeros objetos da cultura, da pornografia gay internacional à novela das sete. Passando, naturalmente, pelos escritos acadêmicos.

Consideremos, mesmo que provisoriamente, estes discursos sobre raça, cultura e sexualidade como se entrelaçando em uma "formação discursiva", aberta e em contestação, multiplicada em diversos mecanismos e estratégias de enunciação e articulação, confundindo $e$ atravessando os gêneros narrativos e dando forma e conteúdo concretos a relações de poder, assim como a produção de sujeitos, objetos e normas de regulação entre estes. Como um sistema de enunciados, esta formação discursiva da raça, da cultura e da sexualidade, compreendida sob o tema geral da miscigenação, é uma reunião de discursos, entendidos como acontecimentos discursivos que produzem efeitos e se associam a estes efeitos concretos. Como um sistema de dispersões estes conjuntos discursivos são revelados pelos distanciamentos $e$ afastamentos diferenciais, segundo procedimentos de produção

${ }^{21}$ PARKer, Richard G. Corpos, Prazeres e Paixões. A cultura sexual no Brasil contemporâneo. São Paulo, Best Seller, 1991. 
de objetos, o "Problema Negro" por exemplo, e de regras de produção, a mestiçagem $e$ a sexualidade. Estas regras $e$ procedimentos são, ao mesmo tempo, discursivos e nãodiscursivos:

As relações discursivas, vê-se, não são internas ao discurso: não religam entre si os conceitos ou as palavras; elas não estabelecem entre as frases ou as proposições uma arquitetura dedutiva ou retórica. Mas não são, entretanto, relações exteriores ao discurso que o limitariam, ou the imporiam certas formas, ou o forçariam em certas circunstâncias a enunciar certas coisas. Elas estão, de alguma maneira, no limite do discurso. ${ }^{22}$

Estabelecido no limite ou nas fronteiras do discurso como um campo separado dos fatos da linguagem, a discursividade sobre a miscigenação no Brasil produziu o mestiço como um objeto indeterminado, incapaz de propor-se como um sujeito. Este objeto, o mestiço ou a cultura miscigenada, está eivado de componentes raciais e de controle social, é por outro lado, parte da estratégia de bio-poder característica das formações sociais latino-americanas. Revela as marcas particulares da história colonial local neste processo. ${ }^{23}$

Esta bio-política é fonte para os racismos contemporâneos, enquanto políticas de estado e, ao mesmo tempo, está situada no entroncamento da sexualidade, lugar de encontro entre o espécime individual e a espécie. Nesta encruzilhada, abandonada por Exu, intervém o racismo, operando na continuidade biológica da espécie e criando descontinuidades, diferenças administráveis.

${ }^{22}$ Foucault, Michel. A Arqueologia do Saber. Petrópolis, Vozes, 1971, pp.60-61.

${ }^{23}$ WADE, Peter. Orden Racial e Identidad Nacional. In: Gente Negra, Nación Mestiza. Dinámicas de las identidades raciales en Colombia. Instituto Colombiano de Antropologia/Editorial Universidad de Antoquia/Ediciones Uniandes/Siglo del Hombre Editores, 1991, pp.33-60. WRIGHT, Winthrop R. Café com Leche. Race, Class, and National Image in Venezuela. Austin, University of Texas Press, 1996. 
Ora, não parece ser exatamente esse o movimento racializante dos intelectuais, médicos e antropólogos da primeira metade do século XX? Foi a partir da doxa racial, eixo de sustentação das políticas cotidianas de subordinação, que têm sua base na história das relações de classe/raça, ou seja, no escravismo, que estes doutores produziram uma descontinuidade "cientificamente" administrável, sustentada pelo regime de produção de verdade legítimo naquele momento.

Esta racialização discursiva, e no limite do discurso, tem assim dois momentos: 1) a assunção irrefletida, porque imanente à própria estrutura social desigual, da doxa racial, o racismo presente nas esferas do mundo da vida; 2) a produção de um discurso competente, que racionaliza esta presença irrefletida sob a forma de um discurso ideológico e normativo, motivado pelo controle social e que elegeu o mestiço como seu herói. É justamente este movimento que formata as concepções mais arraigadas sobre nossa auto-imagem nacional e das quais temos tanta dificuldade em nos desvencilhar, concepções dramaticamente marcadas pelo peso de sua própria historicidade e que habitam as dobras mais sutis de nossa subjetividade.

Não é necessário muito esforço imaginativo para perceber como Foucault inadvertidamente caracteriza bem o processo brasileiro que mal descrevi acima. A implantação do Estado Republicano no Brasil contou com o concurso de intelectuais para a instalação de uma formação discursiva, determinada como uma estratégia de bio-poder, que produziu as raças no Brasil e o Problema Negro como tipicamente nacional. Este problema foi resolvido em seus próprios termos pelo cultural turn dos anos 3040 , que pode ser claramente interpretado como um esforço de controle de populações e como investimento na administração das raças como forma de solidificar o status quo e os interesses de Estado.

Dizer que o problema foi resolvido em seus próprios termos significa dizer que ele assumiu outras formas, permanecendo presente, ainda que confusamente divisado. A indeterminação 
O efeito do sexo

racial, paradoxalmente produzida pelo discurso raciológico da mestiçagem, acompanha como um espectro o processo social brasileiro e está presente na formação dos processos que procuro discutir em Salvador. O fim do problema negro foi a sua dissimulação. A novidade neste cenário político cultural foi a emergência de novos sujeitos sociais afrodescendentes que, reflexivamente, passaram a produzir suas próprias interpretações sobre si e sobre a história das relações raciais em Salvador, deslocando formas cristalizadas de representação para a raça $e$ para o gênero, como veremos a seguir.

\section{Corpo e gênero: o brau e a beleza negra}

Assumirei que o corpo, enquanto categoria sociológica, configura-se como um objeto marcado pela filiação à proposição feita no artigo clássico de Mauss sobre as técnicas corporais. ${ }^{24}$ Assumir esta filiação implica em conduzir a discussão para um entendimento da constituição do corpo como sendo realizada pela sua relação com o conjunto de técnicas que mediam a sua interação com a natureza e com o self. ${ }^{25}$

Nesse sentido, a formação do corpo, ou a inculcação de técnicas corporais, é parte do processo de individuação, ou formação do indivíduo e do ideal de self, através deste processo a formação do corpo é a reprodução do corpo social. O indivíduo não existe como uma entidade preexistente à sociedade, mas, inversamente, só é possível como uma instância da sociedade

${ }^{24}$ MAUSS, Marcel. As Técnicas Corporais. In: Sociologia e Antropologia. São Paulo, E.P.U./EDUSP, 1974, pp.211-233.

${ }^{25}$ ID., IB.; BRumAnA, Fernando G. Antropologia dos Sentidos. Introdução as Idéias de Marcel Mauss. São Paulo, Brasiliense, 1983; GofmAn, Alexander. A Vague But Suggestive Concept: The Total Social Fact. In: JAMES, W \& ALLEN, N. J. (eds.) Marcel Mauss. A Centenary Tribute. New York/Oxford, Berghahn Books, 1998, pp.63-70. 
desdobrada na forma da individuação. ${ }^{26}$ Neste caso, o corpo está situado como uma instância da reprodução da sociedade, através de um processo de transmissão de estruturas culturais para o suporte da subjetivação mediante o engendramento de práticas determinadas. A sociedade, entretanto, não está entendida como uma entidade discreta, ou um conjunto fixo de padrões e normas, regularidades observáveis, mas como um campo de diferenciações que se representa através de práticas simbólicas específicas, performativas, ideológicas e críticas. A separação entre indivíduo $e$ sociedade pode ser vista assim, como determinada e contingente e como outra face da velha mania ocidental por dicotomias. Indivíduo e sociedade existem como termos de uma relação. Esta relação põe a nu o caráter, também construído, da idéia de sociedade como uma exterioridade plena. Corpo, indivíduo e sociedade são categorias sociais forjadas na confluência de discursos e instituições, sua dissolução crítica revela que sob sua aparência reificada existem processos conflitivos e antagônicos processos racializados, gendered, de classe, etc. - que são constitutivos da experiência social.

E como entender a produção do corpo negro e de práticas corporais racializadas? O corpo negro é um Outro para o self do negro, na medida em que se constitui como representação alienada de si, reflexo pervertido da dominação branca. $\mathrm{Na}$ reafricanização, e em outros lugares, ele está sendo reinventado, substituído, suplementado, na medida em que reinscrevemos nele os signos da historicidade e revertemos o estigma $e$ a corporalidade compulsória a ele atada. A reafricanização têm dado nova inflexão às formas tradicionais de intervenção crítica afrodescendente. O gesto negro como ato subversivo revela,

${ }^{26}$ STRATHERN, Marilyn. For The Motion (1). 1989 Debate: The Concept Of Society Is Theoretically Obsolete. In: INGOLD, Tim. (ed.) Key Debates in Anthropology. London/New York, Routledge, 1996, pp.60-66. 
O efeito do sexo

assim, o corpo como um não-ser, uma fronteira variável e em disputa. $^{27}$

Dito isso vejamos os dois exemplos melhor documentados, e porventura mais significativos, de identidades performadas de raça-gênero na reafricanização, o brau e a beleza negra.

No contexto do processo de reafricanização, a juventude negra de Salvador, em busca de afirmação cultural e modernidade, entrou em conexão com a trend mundial da música negra norte-americana. James Brown e a música funk tornaram-se elementos da cultura negra baiana, agora também elaborada como internacional, jovem, corpórea, articulada na relação com os bens de consumo e com a mídia. ${ }^{28} \mathrm{~A}$ música negra norteamericana comporia a trama dos contra-discursos diaspóricos discutida por Gilroy em $O$ Atlântico Negro. ${ }^{29}$ Em Salvador, estes discursos caíram no solo umedecido pelas tradições locais de interação entre brancos e negros e pelas formas tradicionais de resistência africana na cidade. É neste contexto que jovens pobres e negros passam a fazer uso de roupas e estilos de penteado inspirados na visualidade funk-soul, buscando identidade na articulação com a negritude globalizada, foram chamados de braus, aportuguesamento de brown, rapidamente essa figura atraiu os estigmas da classe média. O brau era o "baixo-astral", feio, de gosto duvidoso e, principalmente, perigoso, com seu cabelo black powere suas correntes "espalhafatosas".

\footnotetext{
${ }^{27}$ BuTLER, Judith.Problemas de Gênero Feminismo e Subversão de Identidade. Rio de Janeiro, Civilização Brasileira, 2003.

${ }^{28}$ SANSONE. Livio. Funk Baiano: Uma versão Local de um Fenômeno Global? In: SANSONE, L. e SANTOS, J. T. dos. Ritmos em Trânsito. Sócio-Antropologia da Música Baiana. Salvador, Dynamis Editorial/ Programa a Cor da Bahia/ Projeto Samba, 1998, pp.219-240. RiséRIO, Antônio. Carnaval ljexá. Salvador, Corrupio, 1981.

${ }^{29}$ Gilroy, Paul. O Atlântico Negro. Modernidade e Dupla Consciência. São Paulo, UCAM/Editora 34, 2001.
} 
Como jovem "disruptor", o brau se faz presente em algumas etnografias contemporâneas. Livio Sansone descreve a sua emergência como a de um

Jovem [negro] de classe baixa que experimentava com o estilo de soul brother na Bahia (...) utilizando roupas ou acessórios atribuídos aos negros norte-americanos, para se diferenciar do visual tradicional Afro-Baiano, digamos assim, sem ter que esposar diretamente um visual tido como branco. ${ }^{30}$

Ari Lima, outro etnógrafo do brau, reproduz um trecho de entrevista com Carlinhos Brown - ele próprio auto-reconhecido como fruto da experiência da soul music em Salvador nos anos setenta - em que o músico conta, como uma espécie de mito de origem, como os jovens na Liberdade interagiam com a música $e$ a imagem de James Brown:

I didn't understand anything he was singing, but I understood how he acted, and everyone understood that, because his dancing, the way he danced, dragging himself along, you know, was like a dribble, like a dribble around social things, going down to the floor, using his whole body like a movement. When you came to Liberdade, some guy would always challenge you: Draw a line! And he'd dance a circle. So if you danced cool, if did a novel step it was all right. If not, everyone messed you and stuff - "You aren't a brau, man"!. ${ }^{31}$

Tanto Lima como Sansone fizeram pesquisa etnográfica em bairros populares em Salvador, Lima no Candeal, berço da

${ }^{30}$ SANSONE. Livio. Funk Baiano... Op. cit., p. 225.

${ }^{31}$ LIMA, Ari. Black or brau: Music and Black Subjectivity in a Global Context. In: PERRONE, Charles e DUNN, Christopher. The Internationalization of Brazilian Music. Gainesville, University of Florida Press, 2001, pp.262. 
O efeito do sexo

Timbalada $^{32}$ e Sansone no Caminho de Areia, na Cidade Baixa, próximo ao tradicional bairro do Bonfim. Ambos ressaltam como a formação da auto-identidade dos jovens teria sido mediada: 1) pela figura de James Brown, 2) por determinada relação entre os pares na afirmação por masculinidade e 3) por uma contestação da sociedade branca dominante, numa afirmação de identidade e modernidade. É curioso que ao mesmo tempo em que essa imagem era incorporada positivamente pelos jovens negros da periferia era detestada e estigmatizada pela classe média branca, que transformou a palavra brau em ofensa ou demérito.

Em dois outros momentos diferentes podemos flagrar breves aparições etnográficas destes braus. numa monografia de graduação datada de 1993, cuja pesquisa de campo foi feita na Massaranduba, antiga favela urbanizada em Salvador, e em 1995, em dissertação de mestrado sobre territorialidades no Pelourinho. No primeiro caso, os braus eram alguns dos jovens moradores da Travessa da Esperança (Massaranduba), associados ao mundo dos pequenos crimes e aproximados de uma masculinidade agressiva e hiper-sexualizada, usando roupas coloridas e correntes no pescoço. No segundo caso, numa comparação entre dois espaços de sociabilidade, eventos-território no Pelourinho, um destes, o Pagode do Espaço Cultural É Proibido Proibir, foi descrito como repleto de braus, em oposição a outro eventoterritório, o Bar Cultural, produzido por uma parcela da juventude branca de classe média, auto-identificada como "alternativa". ${ }^{33}$

${ }^{32}$ Sobre a Timbalada, outro "braço" da reafricanização conferir LIMA, Ari. Espaço, Lazer e Música e diferença cultural na Bahia. Estudos Afro-Asiáticos, n ${ }^{\circ}$ 31, Centro de Estudos Afro-Asiáticos, Rio de Janeiro. 1997; e O Fenômeno Timbalada: Cultura Musical Afro-Pop e Juventude Baiana Negro-Mestiça. In: SANSONE, L. e SANTOS, J. T. dos. Ritmos em Trânsito... Op. cit., pp.161-180.

${ }^{33}$ Evento-território é uma noção descritiva utilizada para destacar os aspectos transitórios e não-substancialistas de declinação de identidade territorializada no Pelourinho em Salvador. Cf. PINHO, Osmundo de A. Espaço, Poder e Relações Raciais: O caso do Centro Histórico de Salvador. Afro-Asia, ns 21/22, Salvador, Bahia, 1999, pp.257-274; e Alternativos e Pagodeiros: Notas Etnográficas sobre Territorialidade e Relações Raciais no Centro Histórico de Salvador. Estudos 
Neste caso, parece ter ficado claro a importância do corpo $e$ da definição de masculinidade para a identidade destes jovens. ${ }^{34}$

Ora, acredito que corpo negro, como um "objeto cultural" deve ser analisado como acoplado à dinâmica geral das lutas discursivas, na medida em que sejamos capazes de reconduzi-lo ao seu contexto e à sua historicidade. ${ }^{35}$ "Ler" o corpo masculino é um desafio de um modo em geral, ler o corpo masculino negro obriga-nos a considerar a complexidade das determinações que, do ponto de vista do agente, orientam suas práticas de gênero, assim como suas performances de identidade. Lê-lo, por outro lado, pressupõe ainda a reposição dos contextos de interação significativos como contextos de dominação e disputa. Para nosso caso, este contexto não é outro se não aquele das desigualdades raciais, do racismo e do Problema Negro, desenvolvidos ao longo da história. Neste contexto, o corpo do brau exerce uma corporalidade subversiva, disruptiva, que investe contra os sentidos pacificadores para o homem, para o negro e para o corpo. ${ }^{36}$

Expondo seu corpo, alterando a aparência do cabelo, exibindo nas ruas as cores agressivas de suas roupas, além de representar como mímica da violência a postura da agressividade, o brau desafia a moral, o bom gosto e o racismo de forma mais ou menos contundente. De forma mais ou menos contraditória, por

Afro-Asiáticos, n ${ }^{\circ}$ 34, Centro de Estudos Afro-Asiáticos - CEAA, Universidade Candido Mendes, Rio de Janeiro, dezembro de 1998, pp.35-48.

${ }^{34}$ PINHO, O. Alternativos e Pagodeiros... Op. cit.; e Espaço, Poder e Relações Raciais... Op. cit.

35 JoHnson, Charles. A Phenomenology of the Black Body. In: GoldSTEIM, L. (ed.) The Male Body. Ann Arbor, The University of Michigan Press, 1994, pp.121-136.

${ }^{36}$ Bordo, Susan. Reading the Male Body. In: Goldsteim, L. (ed.) The Male Body... Op.cit., pp.265-306; CULBERTSON, Philip. Designing Men: Reading the Male Body as Text. http://www.bu.edu./mzank/TextualReasoning/tr-archive/tr7. html/Culbertson1.html, 1999. 
outro lado, reproduz estereótipos sobre si próprio e, talvez, eleja a mulher ou a feminilidade como seu Outro desejado e oprimido.

E a mulher negra não é outro "objeto cultural" menos representado pelos discursos racializados, ocupando, na verdade, lugar central na consolidação da discursividade nuclear sobre a fundação do nacional. Assim é que podemos ver como o ideal nacional no Brasil está intrinsecamente definido em associação a narrativas e modelos de raça e gênero, o que não diverge do processo que encontramos na Bahia.

Podemos dizer que fundadas nesta base se impuseram, através de medidas ideológicas e mesmo da violência material, algumas imagens ou modelos de raça e gênero que comporiam o repertório da nacionalidade e, em conseqüência disso, uma coleção de estereótipos a povoar o imaginário social, colaborando para a fixação de um lugar subalternizante e/ou folclorizante para afrodescendentes. Podemos chamá-las de Imagens de Raça e Gênero, pressupondo que estas se condensaram em representações imediatamente reconhecíveis. Por outro lado, estas imagens se formaram em um limiar ou limite entre acomodação, conflito, resistência e imposição da opressão. Funcionam em muitos casos como verdadeiros constrangimentos sociais definindo posturas, expectativas, carreiras, etc. Nos dias de hoje, dominados pela imagem-espetáculo, a proliferação destas imagens de dominação branca projetadas como imagens negras ganham em amplitude, mas também em ambigüidade, permitindo, porventura, re-invenção e crítica reflexiva. Foi contra algumas destas imagens de raça e gênero que o ideal da Beleza Negra se desenvolveu. Ora, vejamos abaixo algumas destas imagens, relevantes para o caso baiano.

Não é de hoje que chama atenção a recorrência com que na literatura, nas artes, na música popular e alhures, se reinventa um ideal de mulher, que sendo mulata (mestiça), preserva características da sensualidade bestial da negra em modos "afinados" pelo sangue branco. Mariza Corrêa revela como a mulata é pensada como "puro corpo", recém saída do estado 
natural, maliciosa e pura, embaralhando as categorias raciais $e$ sexuais, apresentando-se como um híbrido, que pelo intermédio do sexo cruza as raças e funda uma cultura. A operação de invenção do Brasil, mito fundacional brasileiro, está carregada de significado sexual porque é pensada como a miscigenação racial por via sexual. Ora, a mulata é o símbolo gracioso desta miscigenação que, segundo ocorre, ainda ajuda a revelar o que pretende esconder: a rejeição da "negra preta". ${ }^{37}$

A fixação da mulata não poderia permanecer incólume ao avanço da mercadoria e do espetáculo. Graças à modernidade $e$ aos fluxos transnacionais, a Bahia agora é vista também como um território livre para o safári sexual colonial. Como descreve Antônio Jonas Dias Filho ${ }^{38}$, a própria indústria do lazer e do turismo em Salvador "vende" uma imagem da Bahia e de Salvador associada à figura da mulher desnuda e mestiça, que se oferece entre a rebentação e os coqueiros. A indústria que produz a Bahia como imagem e reduz a cultura baiana a slogans ${ }^{39}$, alimenta-se do mesmo solo que faz florescer outra indústria, a do comércio sexual de mulheres e da prostituição "étnica" em Salvador:

Os alemães, por exemplo, chegam a pagar, por um pacote de quinze dias, o equivalente a 10 mil marcos para conhecer e namorar mulheres baianas, preferencialmente "negras ou mulatas", que apresentam características daquelas que lhes foram mostradas em books, vídeos ou catálogos. Nesse caso também os pré-requisitos exigidos para as mulatas do Sargentelli fazem parte do contrato, só

\footnotetext{
${ }^{37}$ CoRRÊA, Mariza. Sobre a Invenção da Mulata. Cadernos Pagu (6/7), Núcleo de Estudos de Gênero - Pagu/Unicamp, 1996, pp.35-50.

${ }^{38}$ DiAS FilHo, Antonio Jonas. As Mulatas que não estão no Mapa. Cadernos Pagu (6/7), Núcleo de Estudos de Gênero - Pagu/Unicamp, 1996, pp.51-66

${ }^{39}$ PINHO, Osmundo de A. "A Bahia no Fundamental": Notas para uma Interpretação do Discurso Ideológico da Baianidade. Revista Brasileira de Ciências Sociais, vol. 13, n 36, 1998, pp.109-120.
} 
O efeito do sexo

que em Salvador, esse estereótipo racial recai sobre as mulheres denominadas no circuito "morenas-jambo". ${ }^{40}$

Outra "carreira" típica para mulheres negras em Salvador é a de Baiana de Acarajé. A figura feminina folclórica que é a representação por excelência da Bahia ela mesma. ${ }^{41}$ Ora, a Imagem da Bahia é a repetição da imagem da crioula escrava, além de ser, como a mulher que vende acarajés na rua, a descendência das negras ganhadeiras, existindo muito concretamente em cada esquina da cidade. A reprodução de um lugar social subordinado e um lugar cultural folclorizante, caminhou lado a lado e, além de bem documentada, tornou-se o símbolo da cultura local e da identidade dos baianos, brancos ou negros. Bem, a Bahia é a terra das baianas. Lá encontraremos pelas ruas a memória evocada da escravidão, preservada como um nicho profissional para mulheres negras.

Uma das informantes que entrevistei para uma pesquisa anterior era baiana de acarajé, um trecho de seu depoimento ilustra bem como a indústria de turismo reforça a reposição de estereótipos no vivido:

Vendia acarajé, eu comecei a vender acarajé, eu tinha dez anos. (...) E minha mãe conseguiu tirar carteira e me cadastrar, depois fui convidada pela Bahiatursa, trabalhei dentro de uma escuna, em alto mar, quer dizer, tudo aquilo pra mim era fascinante, não era nem pelo dinheiro, era as propagandas que eu ia fazer, ganhar dinheiro. Assim muito eu não pensava: "Pô, vou ser fotografada, sair no jornal, na revista", também quando trabalhava pra Bahiatursa conheci muitos guias, conheci muita gente de fora, gente maravilhosa, gente que dá o merecido valor, entendeu? Não que eu não mereça, que eu não merecesse, eu até que eu mereço, porque eu sou uma pessoa que quando eu me

${ }^{40}$ Dias Filho, A. As Mulatas que não estão no Mapa... Op. cit., p.57.

${ }^{41}$ PINHO, O. A Bahia no Fundamental... Op. cit. 
Osmundo de Araújo Pinho

visto de baiana, vendedora de acarajé, eu me transformo em outra pessoa, não é a Maria brigona, não é a Maria... dona-de-casa, a Maria mãe de filho, ali é a Maria Baiana de Acarajé, entendeu? Porque além de eu ter um sorriso, que eu cativo os fregueses, eu incorporo e eu freto com os fregueses eu chamo com meu tabuleiro assim, só com um sorriso, entendeu? , modo de tratar, então tudo isso eu aprendi dentro da Bahiatursa. (depoimento ao autor, 1993)

Um terceiro, mas não menos prevalecente ícone estereotípico da mulher negra é sem dúvida a empregada doméstica, a criada ou a ama-de-leite. Também nesse caso o motivo é colonial e escravista. A repetição de estereótipos, sua representação e apresentação como alegorias da verdade ou da realidade certamente tornam mais plausíveis os lugares sociais alegorizados por estas imagens.

$\mathrm{O}$ que pareceu tão chocante, e claramente racista, para $\mathrm{F}$. W. Twine ${ }^{42}$, em sua pesquisa sobre racismo no interior do Brasil, parece não só natural ou legítimo, mas até louvável para a maioria dos brasileiros e um motivo quase pio para a representação da negra brasileira e mesmo da cultura nacional: a imagem da ama-de-leite ou, em versão moderna, da empregada que é "como se fosse da família", constantemente atualizada nos discursos, representações, obras literárias e na indústria cultural.

A duplicação dos estereótipos como representação e como destino para algumas destas mulheres sugerem um pesado constrangimento para seu enquadramento social. Na ordem racialsexual naturalizada, o destino das mulheres negras é traçado também pelos estereótipos que acomodam a contradição incorporada em seus corpos $e$ os inscreve no regime local de subordinação.

${ }^{42}$ Twine, France Winddance. Racism in Racial Democracy: The Maintenance of White Supremacy in Brazil. New Brunswick/New Jersey/London, Rutgers University Press, 1998. 
O efeito do sexo

Com o processo de reafricanização e surgimento dos movimentos feministas e negros nos anos setenta, este trio de representações racistas começou a ser finalmente questionado na Bahia. O Concurso de Beleza Negra do Ilê Aiyê e a reinvenção do cabelo negro são dois momentos fundamentais desse processo.

Conforme a literatura parece indicar não foi nada desprezível o trabalho microscópico das trançadeiras $e$ cabeleireiras de bairro, que se multiplicaram pela periferia de Salvador, revertendo a lógica do alisamento, visto pelas mulheres como desconfortável e violento. Independentemente do conteúdo étnico das tranças, estas parecem mais modernas e práticas, comparadas ao ferro quente. Dete, uma das profissionais pioneiras na revalorização do cabelo negro, comenta em entrevista ao jornalista Hamilton Vieira: “... antes do Ilê as mulheres negras se violentavam queimando seus cabelos em ferros quentes $e$ pastas alisantes. Pela influência do bloco isso está acabando". ${ }^{43}$

A sensível monografia de Ângela Figueiredo sobre a economia da trançadeira lança luz sobre a importância que representou para as jovens negras em Salvador a ampliação do repertório de tratamento de cabelos. Antes, o cabelo da negra era, digamos, não-cabelo e deveria ser ou alisado a ferro ou escondido sob o torço, como o cabelo da Baiana de Acarajé. Com a revolução estética produzida pelo "black is beautiful' baiano, o cabelo da negra passou a ser a fronteira de uma luta simbólica pela afirmação da Beleza Negra, daí para frente um conceito quase nativo.

A Beleza Negra ganha uma conotação altamente politizada, porque quer produzir uma inversão ou fissura na cadeia de significação que encadeava negro-primitivo-feio-inferior. Depois do Ilê e de suas "negras de trança", a mulher negra passou a contar com outras imagens de afirmação de identidade e de construção de si ancoradas na re-invenção do cabelo.

${ }^{43}$ VIEIRA, Hamilton. Negro. A consciência necessária. A Tarde, Salvador, 20 de novembro de 1987, caderno 2. 
Figueiredo ${ }^{44}$ aponta ainda para outro fator fundamental para reconstrução do cabelo negro, o papel da indústria cultural e da oferta crescente de produtos de beleza destinados ao cabelo crespo, ou seja, "nossa velha inimiga, a mercadoria" 45 , faz sua aparição auto-contraditória. No verão, aliás, a estética da trança afro é abundantemente mercadificada e comercializada, sendo vendida a turistas brancos ou negros. Como vemos neste trecho: "Não tem mais esse negócio de cor, hoje todo mundo usa penteado afro', entusiasma Negra Jhô, uma das cabeleireiras mais conhecidas do pelourinho". ${ }^{46}$

Ora, o mercado e o acesso ao mercado sob forma de consumo parece ser um aspecto importante na constituição de uma moderna classe média negra, como uma nova identidade negra e modernizada, como Fry e a mesma Ângela Figueiredo parecem indicar. ${ }^{47}$ Esta última desmistifica, inclusive, a oposição entre inclusão social e embranquecimento, demonstrando como a ascensão social muitas vezes intensifica o processo de identificação racial e re-invenção estética de si. ${ }^{48}$ Para Fry, por outro lado, o investimento da mídia e da publicidade parece constituir simbolicamente esse "novo" segmento social, justamente como uma classe média negra, identitária e polarizada em relação aos

\footnotetext{
${ }^{44}$ Figueiredo, Angela. Beleza Pura: Símbolos e Economia ao Redor do Cabelo Negro. Monografia de Graduação em Ciências Sociais, UFBa, Salvador, 1994.

${ }^{45}$ DeBord, Guy. A Sociedade do Espetáculo. Comentários sobre a Sociedade do Espetáculo. Rio de Janeiro, Contraponto, 1998

${ }^{46}$ RiBAS, Beatriz. Tramas e Tranças, Jeitinho de Ser Baiano. Viver Bahia. Cultura, Turismo e Lazer, ano 1, no 45, 1999, p.27.

${ }^{47}$ FRY, Peter. Estética e Política: Relações entre "Raça", Publicidade e Produção de da Beleza no Brasil. In: Goldenberg, Mirian. (org.) Nu \& Vestido. Dez antropólogos revelam a cultura do corpo carioca. Rio de Janeiro, Record, 2002, pp.303-326.

${ }^{48}$ Figueiredo, Angela. Velhas e Novas "Elites Negras". In: MAIO, M. C. \& BÔAS, G. V. (orgs.) Ideais de Modernidade e Sociologia no Brasil. Ensaios sobre Luiz Aguiar Costa Pinto. Porto Alegre, Editora da Universidade Federal do Rio Grande do Sul, 1999, pp.109-124.
} 
O efeito do sexo

brancos, ao mesmo tempo em que diferenciada da tradição do gradualismo racial brasileiro:

Eu diria que Raça Brasil e os produtos que visam a desenvolver uma estética negra desempenham um papel fundamental na disseminação da taxonomia bipolar e na redefinição de "mulatos", "pardos", "cafuzos", "morenos", toda a gama de categorias raciais tradicionais, em "negros" apenas. Além disso, Raça Brasil e toda parafernália cosmética se esforçam bastante para batizar, criar $e$ transformar a "classe média negra" de mero efeito estatístico em fato socialmente significativo. ${ }^{49}$

É difícil negar que, de um modo ou de outro, algum conceito de Beleza Negra se constrói entre a mídia e a indústria cultural. Também nesse caso a Beleza Negra é moderna e orgulhosa, mas aqui, diferentemente do contexto da negritude politizada do Ilê, está presa a um estilo de vida afluente e a exposição de bens como indicador de integração social. $\mathrm{O}$ conceito de Beleza Negra, suspenso assim entre o discurso de reinvenção identitária do Ilê Aiyê e a reposição da subjetividade pela indústria cultural, tem operado através destes contextos complexos e voláteis como neutralizador de antigos estereótipos produzidos como representações da mulher negra. Estes estereótipos ganham corpo e dimensionalidade na superfície do repertório tradicional das imagens racistas no Brasil. Não é de se estranhar, dessa forma, que essa mesma superfície se revele como o espaço onde a reversão através das imagens possa se dar. Ora, esta reversão não se realiza sem atualizar outras contradições, de um lado por um certo tipo de essencialização da Beleza Negra no discurso visual do $I l \hat{e}^{50}$, de outro, na associação entre a Beleza e a Mercadoria.

${ }^{49}$ FrY, P. Estética e Política... Op.cit., p.316.

${ }^{50}$ AgIER, Michel. Anthropologie du Carnaval. La Ville, La Fête et L'Afrique à Bahia. Marseille, Éditions Parenthèses, 2000. 
A agência afrodescendente em Salvador, materializada como uma prática performativa em contextos sociais complexos, reinventa, no intervalo da significação ou no espaço da ambivalência, a destruição do signo $e$ a negociação no interior da ambigüidade. Os sentidos da beleza negra e da corporalidade têm sido revertidos e submetidos a um bombardeio incessante de ressignificações. O lugar da mulher negra força os limites de sua representação para expor a cristalização alienada da representação do corpo feminino como mulata, doméstica ou baiana, revertendo para a versão afirmativa da Mulher Étnica do Ilê Aiyê. Nesta mesma brecha outros discursos reinventam a Beleza Negra com vistas à formação da subjetividade ancorada na mercadoria e na representação diferida de si como valor. A cada momento, um novo marco ou diferença se interpõe mais além, a cada momento a agência anônima e dispersa das mulheres amplia esta fronteira para algum outro lugar sempre reposto $e$ não alcançado. 